\title{
UMA TEORIA DO DIREITO ADMINISTRATIVO. DIREITOS FUNDAMENTAIS, DEMOCRACIA E CONSTITUCIONALIZAÇÃO. BINENBOJM, GUSTAVO. 2. ED. RIO DE JANEIRO: RENOVAR, 2008. 341 PÁGINAS
}

\begin{abstract}
Vinícius Figueiredo de Souza
Advogado e Diretor Jurídico da Empresa Atrio Rio Service Tecnologia e Serviços. Palestrante, Professor e Consultor Jurídico na área de Direito Público. Foi Procurador-Geral do Município de Mesquita e do Município de Casimiro de Abreu. Graduado em Ciências Jurídicas pela Universidade do Brasil (UFRJ - Rio de Janeiro, RJ) e Graduando em História pela Universidade Federal Rural do Rio de Janeiro (UFRRJ - Seropédica, RJ). Especialista em Direito do Estado pela Universidade do Estado do Rio de Janeiro (UERJ - Rio de Janeiro, RJ) e Pós-Graduando em Direito Administrativo pela Universidade Cândido Mendes (UCAM Rio de Janeiro, RJ). E-mail: <vinifigueir@gmail.com>.
\end{abstract}

Resumo: Em livro instigante, que coloca em xeque diversos paradigmas do direito público, Gustavo Binenbojm descreve diversos institutos jurídicos, bem como sua mutação através dos anos. 0 autor contesta a experiência jurídica contemporânea, demonstrando o pecado original da gênese do direito administrativo e a dogmática a serviço dos donos do poder. Questiona, como afirmado pela geração anterior de administrativistas, o valor do princípio da supremacia do interesse público sobre o privado. O livro trata de outras questões teóricas: da legalidade administrativa, da dicotomia vinculação x discricionariedade e da superação da Administração unitária. Nele são retratados a importância dos direitos fundamentais no exercício da função administrativa e a democracia como elementos estruturantes do estado democrático de direito. O fio condutor da obra é o fenômeno da constitucionalização do direito, a centralidade dos direitos fundamentais e a democracia, servindo como premissas teóricas para as mudanças de paradigmas propostas.

Palavras-chave: Direito administrativo. Direitos fundamentais. Neoconstitucionalismo.

Gustavo Binenbojm é professor adjunto de Direito Administrativo da Universidade do Estado do Rio de Janeiro, Master of Laws pelo Yale Law School e Procurador do Estado do Rio de Janeiro. Além disso, possui papel relevante no mundo jurídico, atuando em casos de candente importância para a sociedade, como na Ação Direta de Inconstitucionalidade no 4.815, em que questiona, junto ao Supremo Tribunal Federal, a constitucionalidade da exigência de autorização prévia para a publicação de biografias, representando a entidade proponente da ação, Associação Nacional de Editores de Livros - ANEL. 
A publicação da obra Uma Teoria do Direito Administrativo - prefaciada pelo grande constitucionalista Luís Roberto Barroso e fruto do projeto de doutoramento do autor - propõe-se a debater diversas ideias-chave do direito administrativo, colocando em xeque várias certezas por muito tempo difundidas no discurso jurídico. $O$ autor não pretende fazer um debate apartado da corrente dominante, mas questiona sua teoria, apontada como inconsistente do ponto de vista lógico-conceitual; autoritária, do ponto de vista político-jurídico; e ineficiente, de um ponto de vista pragmático. Mas não há como negar que Gustavo Binenbojm apresenta um trabalho ímpar, com inúmeras visões próprias e muito bem inspiradas.

A obra busca romper com diversos paradigmas sedimentados na dogmática jurídica, que são entoados como mantras para os alunos da graduação nos cursos jurídicos nacionais. O autor desconstrói diversos valores preservados como absolutos pelos administrativistas. A obra significa um marco na afirmação do pós-positivismo no campo jurídico, em especial no direito público.

Logo no início, o autor desconstrói a própria gênese do direito administrativo, cultivada por muito tempo, como "fruto de um milagre" nas palavras de Prosper Weil $(1977$, p. 7). De maneira percuciente, afirma que a origem desse ramo do direito fora fruto mais da autovinculação do próprio Poder Executivo, através da jurisprudência do Conselho de Estado francês, do que limitações heterônomas apregoadas pela separação dos poderes. Com efeito, fica construído um modelo em que a burocracia legisla para si e julga para si mesma. Nesse ponto, fica evidente que a dogmática administrativista estruturou-se a partir de premissas teóricas comprometidas com os interesses dos donos do poder, não se curvando às conquistas liberais, padecendo por um pecado original. Assim, a teoria administrativista fundou-se com base na preservação do princípio da autoridade ainda vigente no antigo regime.

As premissas teóricas de Gustavo Binenbojm na obra são os direitos fundamentais, a democracia, o neoconstitucionalismo e a constitucionalização do direito. Para o autor, os direitos fundamentais e a democracia representam os fundamentos do Estado Democrático de Direito, legitimando-o e estruturando-o, o que inegavelmente impacta no exercício da função administrativa. Por outro lado, o neoconstitucionalismo e a constitucionalização do direito representam a pedra de toque da moderna feição do direito administrativo. Quanto ao primeiro, o livro aponta como seu marco filosófico o pós-positivismo, e seu marco teórico, a expansão da força normativa da constituição e da jurisdição constitucional, bem como a nova dogmática de interpretação constitucional. Quanto ao segundo, a Constituição não apenas fica relegada como suporte de validade para as demais normas, mas também penetra por todo o tecido jurídico, promovendo a reinterpretação de diversos institutos legais. 
Aí o livro parte para o objeto de sua investigação, que inicialmente se debruça para a desconstrução (ou, como querem alguns, a reconstrução) do princípio da supremacia do interesse público sobre o privado, que, durante muito tempo, foi aceito como dogma por diversos publicistas, como, por exemplo, o renomado jurista italiano Renato Alessi (1953, p. 147). Invariavelmente, nos anos iniciais dos cursos jurídicos, os alunos são bombardeados com a afirmação de que, no conflito entre o interesse público e o particular, este último deve ser vencido pelos interesses coletivos, como em exemplos clichês repetidos em diversos manuais da graduação, tais como a desapropriação ou a presunção de legalidade dos atos administrativos.

Gustavo Binenbojm não é pioneiro na desconstrução de tal princípio (o próprio autor dá crédito ao florescimento do debate no Brasil para Humberto Ávila), mas suas ideias sobre a questão possuem forte substrato teórico e novas linhas argumentativas. O ponto nodal de sua crítica refere-se ao fato de que a supremacia do interesse coletivo sobre o particular possui incompatibilidade com o sistema constitucional dos direitos fundamentais. Aqui, a perspicácia da obra mostra-se evidente, visto que o autor declara que uma norma que preconiza a supremacia a priori de um valor, princípio ou direito sobre outros de maneira absoluta não pode ser qualificada como princípio. Pelo contrário, um princípio, por definição, é norma aberta, cujo sentido deve ser ponderado de acordo com as circunstâncias do caso em concreto através das técnicas de interpretação jurídica. Fica claro que a prevalência apriorística e descontextualizada de um princípio sobre outro constitui uma contradição em termos.

Fora esta crítica estrutural, o texto foca na inter-relação entre os interesses coletivos e individuais, demonstrando o autor que a promoção dos primeiros importa necessariamente na observância dos direitos de cada um dos cidadãos. De maneira feliz, Gustavo Binenbojm aponta que a relação entre eles não é dicotômica, mas, sim, de mútua influência. A preservação, na maior medida do possível, dos direitos individuais constitui porção do próprio interesse público. Outrossim, deixa evidente que o conceito de interesse público só ganha concretude a partir da disposição constitucional dos direitos fundamentais em um sistema que contempla e pressupõe restrições ao seu em prol de outros direitos, bem como de metas e aspirações coletivas de caráter metaindividual, igualmente contempladas na Constituição.

Fugindo de fórmulas prontas, o livro deixa nas mãos do intérprete e aplicador do direito a função de delimitar o conteúdo do interesse público, a ser delineado pelo processo racional ponderativo através do postulado da proporcionalidade. Neste particular, arejando o debate jurídico, Gustavo Binenbojm segue a linha teórica de Humberto Ávila (2008, p. 30-35), que reconhece a proporcionalidade 
não como um princípio, mas, sim, um postulado normativo, vale dizer: uma norma jurídica de segundo grau.

Veja-se que a tese não nega, de forma alguma, o conceito de interesse público, mas tão somente a existência de um princípio da supremacia do interesse público sobre o privado, visto que a ponderação deve ser feita no caso em concreto de qual interesse deve prevalecer; ponderação a ser feita pelo magistrado, pelo legislador ou pelo administrador, seguindo o roteiro hermenêutico estabelecido pela dogmática jurídica. Assim, fica clara a importância da construção de pilares sólidos na construção de técnicas predefinidas para a solução desse choque, sob pena do conceito de interesse público ficar ao alvedrio de arbitrariedades do intérprete.

No próximo objeto de investigação, a obra foca a crise da lei formal, reconhecendo que se trata de fenômeno universal sobre os diversos segmentos do ordenamento jurídico. O livro aponta diversas causas para a descrença na lei como fonte por excelência do direito, tais como a inflação legislativa e a hipertrofia do Poder Executivo. Gustavo evidencia que tal crise é mais saliente no direito administrativo do que em outros ramos, especialmente pela vinculação positiva do Poder Público à legalidade. Com a constitucionalização do direito, a lei deixa de ser o centro da ordem jurídica, que passa à Constituição. A Administração passa a sujeitar-se não só à lei, mas a todo o ordenamento jurídico, tanto que o autor substitui o termo legalidade por juridicidade, sendo tal mutação relevante para o discurso jurídico, como já fora feito pela Lei no 9.784/1999, que regula o processo administrativo no âmbito da Administração Pública Federal, ao dispor em seu art. $2^{\circ}$, parágrafo único, inciso I, que, no exercício da função pública, os agentes públicos ficam obrigados a observar a lei e o direito.

Após esta feliz troca de nomenclatura, que não representa apenas uma formalidade, mas, além de tudo, uma profunda evolução dogmática, a obra parte para os diversos graus de manifestação da juridicidade: (a) vinculação direta à Constituição; (b) mediante uma intermediação à lei formal; (c) a juridicidade expressada por intermédio de atos administrativos normativos (regulamentos).

Relativamente à juridicidade, o autor leva à baila o clássico debate da existência e constitucionalidade dos regulamentos autônomos, especialmente à luz da Emenda Constitucional no 32/2001. Por fim, destaca a importância do reconhecimento de efeitos jurídicos para situações contrárias à lei, mas que envolvem terceiros de boa-fé, denominando tais casos como juridicidade contra legem. Ainda que tal expressão possa parecer nova para um leitor desavisado, seu conteúdo é similar ao vetusto e conhecido instituto da convalidação administrativa.

A crise da legalidade, como bem destacado pelo autor, representa a dessacralização do mito rousseauniano da lei, como expressão da vontade geral e fundamento único do direito de um povo. 
Ao final, o livro debruça-se sobre dois temas significativos: a dicotomia ato discricionário-vinculado (especialmente o controle judicial dos discricionários) e o panorama da Administração Pública face ao surgimento das Agências Reguladoras.

Como constatado logo no início da obra, o "pecado original" do direito administrativo pode ser notado na feição da própria discricionariedade administrativa, tendo como nascente o espaço decisório real absoluto do Ancien Régime, apartado do escrutínio jurídico. Gustavo, oxigenando o debate, afirma que, com a constitucionalização do direito, não há mais espaço para áreas decisórias da Administração descobertas pelo controle judicial. O livro deixa claro que não há mais espaço para a binária distinção entre ato administrativo vinculado e discricionário, mas para a teoria de graus de vinculação à juridicidade. Gustavo aponta que sindicabilidade do Judiciário de decisões administrativas pode pautarse em standards, como, por exemplo, naqueles campos em que, por sua alta complexidade técnica e dinâmica específica, faleçam parâmetros objetivos para uma atuação segura do Poder Judiciário; em tais hipóteses, a intensidade do controle deverá ser tendencialmente menor. A expertise da burocracia será decisiva na profundidade do controle jurisdicional.

Por fim, dedica espaço à transformação organizacional da Administração Pública, com a ruptura da tradição piramidal do Poder Executivo para uma organização policêntrica, em que as Agências Reguladoras representam seu maior expoente. $\mathrm{O}$ autor, após apresentar o conteúdo desses novos departamentos estatais - especialmente com a sua autonomia -, demonstra que os mecanismos assecuratórios de independência das agências geram três focos de tensão: primeiro, em face do princípio da legalidade (adoção de diversos atos administrativos normativos que muitas das vezes podem invadir o terreno da lei formal); segundo, em face do princípio da separação de poderes (fragilidade de mecanismos políticos de controle das agências); terceiro, em face do regime democrático (ausência de responsividade de seus membros). Arremata, esclarecendo que a autonomia das agências não é um fim em si mesmo, mas apenas uma estratégia de organização do Estado em prol da afirmação dos valores constitucionais.

Ainda que incidentalmente na obra, a participação dos administrados na formação de políticas públicas merecia uma análise mais detida, visto que se trata de tema de relevância capital para o desenho institucional do Estado pós-moderno. Espera-se que, em edições posteriores do livro, tal debate seja nele incluído, especialmente sobre o problema do risco da captura e de novos mecanismos de participação do cidadão.

De maneira muito criativa, Gustavo Binenbojm, logo no primeiro capítulo, afirma que, diante da evolução contraditória do direito administrativo, sua dogmática deve ser colocada no divã. A feliz figura de linguagem consegue resumir bem a proposta de Uma Teoria do Direito Administrativo em erigir novos paradigmas para a 
disciplina dotados não apenas de maior consistência teórica, mas comprometidos com o sistema democrático e a promoção dos direitos fundamentais.

\begin{abstract}
In exciting book that calls into question many paradigms of public law, Gustavo Binenbojm describes various legal institutions, as well as its changing through the years. The author challenges the contemporary legal experience, demonstrating the original sin of the genesis of administrative law and the service of the dogmatic power brokers. Questions, as stated by the previous generation of administrativistas, the value of the principle of supremacy of public interest over private. The book deals with other theoretical issues: the administrative legality, linking $x$ discretion dichotomy and overcoming unitary administration. It is portrayed the importance of fundamental rights in the exercise of administrative function and democracy as structural elements of the democratic rule of law. The underlying theme of the work is the constitutionalization of the right phenomenon, the centrality of fundamental rights and democracy, serving as theoretical premises for paradigm shifts proposals.
\end{abstract}

Keywords: Administrative law. Fundamental rights. Neoconstitutionalism.

\title{
Referências
}

ALESSI, Renato. Sistema istituzionale del diritto amministrativo italiano. Milano: Giuffrè, 1953.

ÁVILA, Humberto. Teoria dos princípios: da definição à aplicação dos princípios jurídicos. 8. ed. São Paulo: Malheiros, 2008.

BINENBOJM, Gustavo. Uma teoria do direito administrativo: direitos fundamentais, democracia e constitucionalização. 2. ed. revista e atualizada. Rio de Janeiro: Renovar, 2008.

WEIL, Prosper. O Direito Administrativo. Trad. Maria da Glória Ferreira Pinto. Coimbra: Almeidina, 1977. 